\title{
Reducing duration of untreated psychosis: care pathways to early intervention in psychosis services
}

Max Birchwood, Charlotte Connor, Helen Lester, Paul Patterson, Nick Freemantle, Max Marshall, David Fowler, Shôn Lewis, Peter Jones, Tim Amos, Linda Everard and Swaran P. Singh

\section{Background}

Interventions to reduce treatment delay in first-episode psychosis have met with mixed results. Systematic reviews highlight the need for greater understanding of delays within the care pathway if successful strategies are to be developed.

\section{Aims}

To document the care-pathway components of duration of untreated psychosis (DUP) and their link with delays in accessing specialised early intervention services (EIS). To model the likely impact on efforts to reduce DUP of targeted changes in the care pathway.

\section{Method}

Data for 343 individuals from the Birmingham, UK, lead site of the National EDEN cohort study were analysed.

\section{Results}

A third of the cohort had a DUP exceeding 6 months. The greatest contribution to DUP for the whole cohort came from delays within mental health services, followed by helpseeking delays. It was found that delay in reaching EIS was strongly correlated with longer DUP.

\section{Conclusions}

Community education and awareness campaigns to reduce DUP may be constrained by later delays within mental health services, especially access to EIS. Our methodology, based on analysis of care pathways, will have international application when devising strategies to reduce DUP.

\section{Declarations of interest}

None.
Treatment delay following a first episode of psychosis (duration of untreated psychosis, DUP) has been the focus of research for over 20 years, since the progenitor study of Johnstone and colleagues in the UK. ${ }^{1}$ Subsequent international research has confirmed that DUP: remains between 1 and 2 years; ${ }^{2-4}$ accounts for variation in outcome at 12 and 24 months, ${ }^{5}$ with studies suggesting that it can affect remission, positive symptoms and social functioning up to 8 years later; ${ }^{6}$ and is linked to risk of harm to self or others. $^{7-9}$ Reducing DUP has become an international target. ${ }^{10}$ However, reducing DUP using community education and awareness campaigns has met with mixed results, ${ }^{11}$ with evidence suggesting that neither general practitioner (GP) education ${ }^{12}$ nor dedicated early intervention services (EIS $)^{13}$ by themselves reduce DUP or generate more treated cases. In exploring the reasons for these mixed findings, it has been argued that attention should be given to the component delays that contribute to DUP, such as individual help-seeking delays and delays within services, as well as its total duration. ${ }^{14}$ It cannot be assumed that these delays will have an equal impact on overall DUP; delays within primary care in the UK, for example, form only a small proportion of overall DUP, considerably less than delays in initial help-seeking or within mental health services. These component delays of DUP are likely to vary across different countries or service configurations; however, despite this variation, a systematic review of international studies ${ }^{15}$ concluded that a common theme is the need to understand the barriers faced when seeking help for psychosis especially the response of service providers. Improving access to treatment at the first episode of psychosis is one of the main aims of early intervention teams. ${ }^{16}$ Although these teams are routinely provided, both in the UK and internationally, for the engagement and treatment of first- episode psychosis, ${ }^{16}$ there is no evidence that they have reduced DUP. ${ }^{11}$ It is not understood why this might be the case. When considering DUP reduction strategies investigation of the outlying cases is especially critical: studies typically find a substantially longer mean than median DUP, with the mean inflated by a group of outliers with very long DUP, often of several years. ${ }^{17}$ Long DUP has been highlighted as a key indicator of outcome, specifically in terms of improved treatment response. ${ }^{5,18,19}$ And, although to date no definitive 'critical period' of DUP has been universally agreed, Lloyd-Evans et $a l^{11}$ indicate that, 'Greater understanding of the characteristics of people with long DUP and how they are eventually initiated into treatment could inform interventions specifically to achieve this aim?

Our aims where therefore to: (a) document DUP and its component delays, and their link with delay in accessing specialised early intervention in psychosis teams; (b) identify an outlier cohort and test whether they present with more severe psychotic symptoms; and whether their long DUP is accounted for by one, or more, of the component delays; (c) identify the sources of delay in the treatment of first-episode psychosis within mental health services, including access to specialist early intervention teams; and (d) model the impact on DUP of reducing the component delays.

\section{Method}

Setting

Birmingham, UK, has a population of 1.05 million and a high degree of cultural diversity. The most recent data available on population by ethnic group is from the Office of National Statistics 2008-2009 mid-year population estimates. ${ }^{20}$ This includes $68 \%$ White British residents, 20\% residents of Asian or Asian British heritage and 7\% Black or Black British and a higher number of residents from the Muslim faith than any other UK local authority. Birmingham is served by a single mental health service, the 'blueprint' for the National Service Framework for Mental Health, ${ }^{21}$ with a number of community services including 
EIS, home treatment and assertive outreach teams. Birmingham's service for first-episode psychosis ${ }^{22}$ was chosen for study as it was the progenitor of such services in the UK; its maturity enables us to address questions concerning its position in the care pathway for psychosis and its impact on DUP.

\section{Design}

This is a cross-sectional study of DUP and care pathways established retrospectively at entry into services. Data are from the Birmingham site of the National Institute for Health Research (NIHR) National EDEN cohort study multisite evaluation of differently configured EIS across sites in England. ${ }^{23}$ All data were collected at entry into EIS.

\section{Sampling}

All participants in the National EDEN study were clients receiving care from Birmingham EIS and recruited into the National EDEN study between August 2005 and June 2009. None were acutely ill and all were interviewed within 3 months of entry into EIS. Participants met ICD-10 criteria $^{24}$ for a schizophrenia spectrum disorder, were aged 14-35 years and were accepted by the specialist early psychosis teams following management of their acute crisis by a home treatment team or admission to psychiatric hospital. These criteria are those followed by all EIS in the UK.

\section{Measures}

\section{Structured Clinical Interview for Positive and Negative Syndrome Scale (SCI-PANSS)}

This is a widely used measure of psychosis comprising 30 items rating severity of positive symptoms (7 items; range 7-49), negative symptoms (7 items; 7-49) and general psychopathology (16 items; range 16-112). It takes approximately $30-45 \mathrm{~min}$ to complete. It has good reliability, criteria-related validity and construct validity. ${ }^{25,26}$

\section{Pathways to care and 'route timeline' analysis}

Pathways to care were assessed using the method of Gater et $\mathrm{l}^{27}$ in which systematic information is gathered from direct interview and electronic healthcare records about the source, sequence and timing of help-seeking by patients and their families, including help-seeking contacts, the main problems presented and treatments offered. This included the sequence and duration of contacts within the mental health service. We also documented any mental health service contact prior to the formal onset of psychosis. These data were synthesised onto visual 'route timelines'; these presented the sequence of help-seeking contacts, referrals made, diagnoses offered, treatment provided and outcomes.

\section{Duration of untreated psychosis}

The DUP methodology was based on that described by Larsen et $a^{28}$ and used in the National EDEN study. ${ }^{23}$ Graduate research psychologists who had completed comprehensive training conducted interviews and DUP calculations to acceptable reliability. Research staff in National EDEN underwent an annual check on DUP reliability. This required each researcher to submit five randomly selected timelines and DUP calculations to National EDEN coordinators in Birmingham, for concordance and standardisation of calculation.

\section{Definition of DUP and component delays}

We defined DUP as the time period between onset of psychosis and the onset of criteria treatment. The definition of these time points is as follows:

(a) Onset of psychosis:

(i) one positive symptom (SCI-PANSS positive 1 to positive 7) rated as moderate or above (4 or above), or

(ii) a cluster of positive symptoms (positive 1 to positive 7) reaching a total rating of 7 or more (not rating absent symptoms). The cluster required at least one of the symptoms positive 1 , positive 2 or positive 3 to qualify as onset of psychosis.

(b) Onset of criteria treatment: the date when adequate treatment commenced (as recorded in healthcare records), which was:

(i) adhering to dosage levels recommended by British National Formulary ${ }^{29}$ guidelines, and either,

(ii) continued for a period of at least 1 month, or

(iii) led to significant reduction in symptoms as measured by SCI-PANSS. ${ }^{25}$ (This option, however, was, in practice, never used.)

Delay in help-seeking. This was the interval between the first help-seeking contact for psychosis and onset of psychosis. Where individuals were already in contact with services (for example for prodromal symptoms) at the onset of psychosis, delay in help-seeking for psychosis was set to 0 .

Delay in first referral to mental health services. This was the interval between the first help-seeking contact and first referral to mental health services. Where individuals were already in contact with services for other symptoms, delay in help-seeking pathway was set to 0 .

Delay within mental health services. This was the interval between the first contact with secondary mental health services after the onset of psychosis and the onset of criteria treatment. Where the individual was already in contact with services (for example for symptoms presented during the prodrome), the contact, which coincided with the time of onset of psychosis, was taken as the onset of mental health services delay.

Delay in accessing EIS $\left(T_{1}\right)$. This was the interval between the first help-seeking contact and acceptance by EIS.

Delay in accessing EIS $\left(T_{2}\right)$. This was the interval between the first contact with secondary mental health services and acceptance by EIS.

\section{OPCRIT}

The OPCRIT ${ }^{30}$ computer programme facilitates a polydiagnostic approach to research on severe psychiatric disorders suitable for multisite studies. It comprises a 90-item checklist of 'lifetime' signs and symptoms that generate diagnoses according to the operational criteria of 12 major classificatory systems (including DSM-IV ${ }^{31}$ and ICD-10 $0^{24}$ ). Good levels of reliability have been reported within all classifications (for example: DSM-III-R, ${ }^{32}$ kappa $(\kappa)=0.73$; ICD-10, $\kappa=0.70)$.

\section{Statistical analysis}

Data were analysed using SPSS (version 18.0) and Stata for Windows. Where appropriate, $\log _{e}$ transformation of DUP was employed, because of marked non-linearity in the response 
variable; examination of non-linearity in response for both positive and general SCI-PANSS subscores in relation to their DUP data was subsequently conducted. An applied stepwise selection process with Schwarz Bayesian Information Criterion was conducted. This method was chosen as it was designed to avoid overfitting the model to the data, hence, reducing the likelihood of non-replicable results.

Analysis of variance (ANOVA) was used to explore the relationship between service pathways and subsequent delays in receiving treatment, and to explore any association between gender, age at onset, ethnicity and living status in terms of mental health service delay

\section{Results}

\section{Participants}

Of the 519 clients accepted into Birmingham EIS between August 2005 and June 2009, 474 clients could be contacted to seek consent and $348(73 \%)$ clients agreed to take part, comprising $255(73 \%)$ males and $93(27 \%)$ females. The mean age at onset was 21.6 years (s.d. =4.4). The DUP of five clients could not be completed due to insufficient information and so these individuals were removed from the analysis, leaving a final sample of 343 participants (72\%). The sample included 137 (40\%) White, 47 (13.5\%) Black, $121(35 \%)$ South Asian, $21(6 \%)$ mixed heritage and $17(5 \%)$ 'other' participants. There were no differences between those who consented and those who did not, in age, gender or ethnicity. The OPCRIT diagnoses included schizophrenia (66\%), schizoaffective diagnoses (18.4\%) and affective psychoses (15.3\%).

\section{Duration of untreated psychosis for the complete cohort}

A median DUP of 50 days was recorded, including low median delays in help-seeking, first referral to mental health services and delay within mental health services (Table 1). However, there was a considerable disparity between mean and median figures and a large standard deviation in all DUP components, suggesting the presence of outliers.

An applied stepwise selection process with Schwarz Bayesian Information Criterion was conducted for the whole Birmingham cohort $(n=343)$, examining sociodemographic factors (age, gender, ethnicity) and symptomatology (SCI-PANSS subscales) in relation to DUP; $\log _{e}$ transformation of DUP was used because of marked non-linearity in the response variable. We examined non-linearity in response for both positive and general SCI-PANSS subscores but overall fit was not improved. Two significant variables emerged in relation to DUP. Longer DUP was linked to more severe SCI-PANSS positive symptoms at entry into the National EDEN study (estimate: $144.9,95 \%$ CI 46.03 to $243.8, P=0.004$ ) and younger age at onset (estimate: $-697.6,95 \% \mathrm{CI}-888.7$ to $-509.5, P<0.0001)$.

\section{The outlier cohort}

Although no 'critical period' of DUP has been definitively established, the literature suggests that improvements in outcome, achieved from reducing DUP from 6 months to 1 month, are comparable with those achieved by reducing DUP from 6 years to 1 year. ${ }^{18}$ In light of these findings, we identified an outlier cohort using a DUP cut-off point of 6 months, in order to represent the point beyond which the likelihood of poor outcome is likely to increase. In total 115 (34\%) clients exceeded 6 months of DUP and 228 (66\%) were below this cut-off. Table 1 shows that patients with a DUP $\geqslant 6$ months, had an overall treatment delay approaching 2 years (mean 704 days; median 518 days), whereas those with a DUP $<6$ months, had a very short mean (36.6 days) and median (19 days) DUP.

The group with a DUP $\geqslant 6$ months experienced long delays in help-seeking, delays within mental health services including accessing EIS, but a relatively short delay in obtaining an initial mental health service referral, usually from the GP (Table 1). There were no significant differences between short and long DUP groups in age, gender, ethnicity, religion or living status, although those with a DUP greater than 6 months had a younger age at onset (19.9 v. 21.1 years, $P=0.016)$. Notably, $64(60 \%)$ of the group with DUP $\geqslant 6$ months had an onset between the ages of 16 and 18 years, compared with $59(27 \%)$ in the short DUP group.

In keeping with previous research, those with DUP $>6$ months recorded more severe positive symptoms $(F=5.58$, d.f. $=1,314, P=0.019)$ and general psychopathology $(F=6.52$, d.f. $=1,311, P=0.011)$ at entry into the National EDEN study. The difference in positive symptoms was equivalent to an effect size of 0.27 and in general psychopathology of 0.30 .

\section{Determinants of treatment delay within mental health services}

The nature of the first service contact

The first point of contact within mental health services comprised two broad groups: (a) 'generic mental health teams' (community mental health teams (CMHTs), $n=164(48 \%)$ and child and
Table 1 Duration of untreated psychosis (DUP) and component delays

\begin{tabular}{|c|c|c|c|c|c|c|c|c|c|c|c|c|}
\hline & \multicolumn{2}{|c|}{ DUP } & \multicolumn{2}{|c|}{ Delay in help-seeking } & \multicolumn{2}{|c|}{$\begin{array}{c}\text { Delay in referral } \\
\text { to mental health } \\
\text { services }\end{array}$} & \multicolumn{2}{|c|}{$\begin{array}{l}\text { Delay within } \\
\text { mental health } \\
\text { services }\end{array}$} & \multicolumn{2}{|c|}{$\begin{array}{l}\text { Delay reaching } \\
\text { EIS }\left(T_{1}\right) \text { (first } \\
\text { help-seeking to } \\
\text { EIS acceptance) }\end{array}$} & \multicolumn{2}{|c|}{$\begin{array}{l}\text { Delay reaching EIS } \\
\left(T_{2}\right) \text { (first mental } \\
\text { health referral to } \\
\text { EIS acceptance) }\end{array}$} \\
\hline & Mean (s.d.) & Median & Mean (s.d.) & Median & Mean (s.d.) & Median & Mean (s.d.) & Median & Mean (s.d.) & Median & Mean (s.d.) & Median \\
\hline $\begin{array}{l}\text { All patients } \\
(n=343)\end{array}$ & $260.3(472.5)$ & 50 & $93.8(274.1)$ & 0.00 & $58.1(228.9)$ & 0.00 & $108.7(308.9)$ & 8 & $353.7(607.0)$ & 111 & $187.5(353.4)$ & 49 \\
\hline $\begin{array}{l}\text { Patients } \\
\text { with DUP } \\
<6 \text { months } \\
(n=228)\end{array}$ & $36.6(44.7)$ & 19 & $12.7(27.9)$ & 0.00 & $8.2(55.32)$ & 0.00 & $15.7(28.2)$ & 1 & $267.7(493.1)$ & 66.5 & 144.2 (246.9) & 36 \\
\hline $\begin{array}{l}\text { Patients } \\
\text { with DUP } \\
>6 \text { months } \\
(n=115)\end{array}$ & 704.2 (603.3) & 518 & $254.6(429.7)$ & 66 & $157.0(375.9)$ & 4 & $292.6(482.1)$ & 141 & $510.1(760.1)$ & 212 & $273.3(492)$ & 87 \\
\hline
\end{tabular}


adolescent mental health services (CAMHS), $n=22(6 \%))$; and (b) 'crisis teams' (home treatment teams $(n=84(24 \%)$ and psychiatric admission units $(n=43(13 \%))$. For $30(9 \%)$ participants, first mental health contact included a variety of non-statutory counsellors, psychotherapists and youth support agencies.

Table 2 shows overall DUP and delays associated with each of these service pathways. Analysis of variance found a significant difference between these pathways in predicting delay in mental health services $(F(5,336)=4.36, P<0.001)$ and overall DUP $(F(5,337)=3.98, P=0.002)$. This was accounted for by a significantly shorter delay associated with first referrals to crisis teams compared with generic teams in adult services or CAMHS.

An applied stepwise selection process with Schwarz Bayesian Information Criterion was conducted with DUP as the response variable. Accounting for gender, age at onset, ethnicity and living status, the type of service received at the first contact with mental health services was found to be a significant predictor of DUP for the whole sample with home treatment, in particular, linked to the lowest DUP. Using home treatment as the comparator, first contact via CMHT was linked to a relative DUP of 319 days (95\% CI 126.65-513.05, $P=0.0012$ ); and first contact via CAMHS a relative DUP of 363.49 days (95\% CI 93.22-633.75, $P=0.0085)$.

\section{Delay in accessing EIS}

Following entry into mental health services, a mean delay of 188 days was observed before acceptance by EIS (Table 1). In total $204(59 \%)$ clients received criteria treatment at least 1 month before reaching EIS and 139 (41\%) clients did not receive criteria treatment until they reached EIS, most doing so within 4 weeks of acceptance (Table 3). Twenty-six (7.6\%) received criteria treatment 2 months or more after EIS acceptance. The delay in reaching criteria treatment within mental health services was strongly correlated $(r=0.68, P<0.001)$ with delay in accessing EIS $\left(T_{2}\right)$, following referral to mental health services when psychotic.

Table 2 shows that those whose first referral within adult services was to a CMHT, experienced the longest delays in accessing EIS; the shortest delays occurred when first contact was the home treatment team. In total $84 \%$ of clients whose first referral was to a home treatment team, were next referred to EIS; compared with $48 \%$ of those whose first referral was to a CMHT. Overall, delay in accessing EIS would appear, therefore, to directly contribute to DUP.

\section{Sources of delay within CMHTs}

There were 164 clients whose first contact with mental health services was a CMHT. A total of $70 \%$ of these had clear psychotic symptoms recorded by their psychiatrist in their healthcare records; a further $11 \%$ were recorded as having 'possible' psychotic symptoms. For $98 \%$ of these clients this contact resulted in one of the following three outcomes: (a) referral to a home treatment team; (b) discharge back to the GP because of either non-attendance or not found to have a mental health problem, or referral to an external service such as youth counselling; or, (c) referral to EIS.

Table 4 shows significant differences between these three CMHT outcomes in terms of mental health service delay $(F(2,105)=8.30, \quad P=0.001)$. As expected, those who were discharged from these teams (with untreated psychosis) experienced the longest delay.

\section{Modelling the impact of reducing component delays on overall DUP}

We attempted to understand the relative impact on DUP of reducing each of its significant components. This analysis is particularly relevant to the development of interventions to understand the scale of change required to bring individuals with long DUP to below what may be a 'critical' threshold. We focus on help-seeking delay and delay in mental health services of those with DUP of more than 6 months, since these emerged as the main components of their DUP (Table 1).

Reducing delays in help-seeking and within mental health services

We undertook a sensitivity analysis to model the impact of reducing mental health service and help-seeking delays on DUP and the scale of change necessary to reduce the numbers of those

\begin{tabular}{|lcc|}
\hline Table 2 Delays associated with first mental health service contact & Mean (s.d.) \\
\cline { 2 - 3 } First mental health service contact & $\begin{array}{c}\text { Delay within mental } \\
\text { health services }\end{array}$ & $\begin{array}{c}\text { Delay reaching early } \\
\text { intervention services }\end{array}$ \\
\hline Community mental health team $(n=164)$ & $174.37(411.04)$ & $469.23(727.76)$ \\
\hline Child and adolescent mental health services $(n=22)$ & $205.95(326.58)$ & $360.36(376.23)$ \\
\hline Home treatment team $(n=84)$ & $21.52(62.22)$ & $173.30(299.30)$ \\
\hline Psychiatric hospital $(n=43)$ & $36.25(97.03)$ & $313.79(639.75)$ \\
\hline
\end{tabular}

\begin{tabular}{|c|c|c|c|c|}
\hline Criteria treatment after $(+)$ or before $(-)$ acceptance by EIS & DUP $>6$ months $(n=115)$ & DUP $<6$ months $(n=228)$ & Total $n$ & $\%$ \\
\hline +3 months & 16 & 2 & 18 & 5.2 \\
\hline +2 months & 7 & 1 & 8 & 2.3 \\
\hline+1 month & 7 & 3 & 10 & 2.9 \\
\hline At acceptance to EIS & 35 & 68 & 103 & 30.0 \\
\hline-1 month & 13 & 48 & 61 & 17.8 \\
\hline-2 months & 10 & 40 & 50 & 14.6 \\
\hline-3 months & 27 & 66 & 93 & 27.1 \\
\hline Total & 115 & 228 & 343 & 100.0 \\
\hline
\end{tabular}




\begin{tabular}{lccccc} 
Table 4 & Community mental health team response, mental health service delay and duration of untreated psychosis \\
\cline { 2 - 5 } & \multicolumn{2}{c}{ Mental health service delay } & & \multicolumn{2}{c}{ Duration of untreated psychosis } \\
\cline { 2 - 5 } Outcome & Mean (s.d.) & Median & & Mean (s.d.) & Median \\
Referred to home treatment team & $92(233.5)$ & 13 & $306(501.3)$ & 68 \\
\hline Discharged & $482.9(784.8)$ & $51(139.7)$ & $431(848.7)$ & 299 \\
\hline Referred to early intervention services & $920(508.1)$ & 203
\end{tabular}

\section{Table 5 Modelling the impact of reducing component delays on duration of untreated psychosis (DUP)}

\begin{tabular}{|c|c|c|c|c|c|}
\hline Delay & 365 days & 180 days & 90 days & 60 days & 30 days \\
\hline \multicolumn{6}{|c|}{$\begin{array}{l}\text { Delay in mental health services } \\
\text { DuP }\end{array}$} \\
\hline Mean (s.d.) & $220.9(377.9)$ & $198.6(366.1)$ & $183.8(361.5)$ & $175.3(359.6)$ & $167(358.5)$ \\
\hline Median & 49 & 49 & 49 & 49 & 32 \\
\hline$n$ (\%) with DUP >6 months & $115(33.5)$ & $115(33.5)$ & $115(33.5)$ & $78(22.7)$ & $74(21.5)$ \\
\hline $\begin{array}{l}\text { Delay in help-seeking } \\
\text { DuP }\end{array}$ & & & & & \\
\hline Mean (s.d.) & $223.5(403.9)$ & 204.6 (392.6) & $191.1(388.7)$ & $184.2(387.6)$ & $177.0(386.8)$ \\
\hline Median & 49 & 49 & 49 & 49 & 37 \\
\hline$n(\%)$ with DUP $>6$ months & 115 (33.5) & 115 (33.5) & $93(27)$ & $89(26)$ & $83(24)$ \\
\hline
\end{tabular}

with DUP of more than 6 months. We did this by systematically 'capping' delays for each individual, starting at 365 days, then, in steps, to 180, 90, 60 and 30 days. For example, if an individual had a mental health service delay of 400 days, this was reduced to 365 days in step one and the impact on total DUP observed.

Although the results (Table 5) show an expected linear reduction in mean DUP as delays were reduced, mental health service delays had the greatest impact on DUP; the percentage of those with long DUP fell only when mental health service delay was reduced to 60 days or less A similar linear reduction in DUP was seen for help-seeking delay; the percentage only diminishing when help-seeking delay was reduced to 90 days or less.

\section{Discussion}

In spite of the long-standing availability of EIS in Birmingham, where the first UK team was introduced in 1994, a third of individuals with a first episode of psychosis had a DUP greater than 6 months. The overall mean DUP of 260 days and a median of 50 is in line with international data. ${ }^{2-4}$ We found that DUP was, paradoxically, prolonged once individuals had entered the mental health system; this included delay in accessing EIS, which strongly correlated with DUP. Thus, the anticipated impact of EIS on reducing DUP appears to be failing in practice due to structural barriers in accessing this specialist service.

\section{Impact of first mental health service contact on DUP}

We examined the impact of first mental health service contact on DUP and access to EIS. First contact with a 'crisis service' (home treatment or admission) predicted shorter subsequent treatment delays within the mental health service and DUP overall. Where first contact was with a (non-crisis) generic mental health team, (CMHT, $48 \%$ or CAMHS, 6\%), substantially longer delays within the mental health services (and overall DUP) were observed. It is important to underline that in all cases, whatever pathway was followed, clients were actively psychotic and untreated. Although we can assume that clients who were first treated via the home treatment team or admission were perceived to be at greater risk, with greater symptom severity, we found that neither gender, age at onset, ethnicity or living status were significant predictors of mental health service delay or DUP. We also found that those accessing crisis services at first contact found their way to the specialist EIS quickly, where criteria treatment was assured, in most cases within a month. These findings are supported by both international and UK findings. ${ }^{33-35}$ We should point out, however, that $59 \%$ of individuals in our study did receive criteria treatment from another mental health service at least 1 month before being accepted into EIS; and that the definition of adequate treatment was identical before and after entry into EIS.

First contact via generic non-crisis services, which occurred in just over half of cases, predicted substantial delays. Unsurprisingly, the singular factor here was early discharge from the CMHT. This occurred in approximately a third of cases, in most instances because clients did not attend out-patient appointments (and the service was unable to outreach the client), but also because a mental health problem could not be elicited, psychosis was not considered or the client was signposted to a non-statutory agency. However, where the client was referred from the CMHT to home treatment or EIS, treatment delay was curtailed.

Community mental health teams are pressured services and have to deal with a wide range of mental health problems. We should not be too surprised by these findings since historical ${ }^{22}$ and recent data ${ }^{23}$ suggest that young people with psychosis do not engage well with out-patient services such as CMHTs and are often discharged as a result. Indeed, the evidence base for the effectiveness of CMHTs in managing schizophrenia was reviewed in recent National Institute for Health and Care Excellence (NICE) guidelines ${ }^{36}$ concluding, 'Despite the fact that CMHTs remain the mainstay of community mental healthcare, there is surprisingly little evidence to show that they are an effective way of organising services. As such, evidence for [or against] the effectiveness of CMHTs in the management of schizophrenia is insufficient to make any evidence-based recommendations' (p. 336). Our findings suggest that care pathways to EIS involving CMHTs may prolong DUP as a result of under-recognition, poor disclosure or disengagement; services associated with reduced delay were crisis and the EIS teams, which have in common assertive and flexible home-based approaches to engagement that young people strongly endorse. ${ }^{2}$

The UK National Health Service Framework for EIS (2001) ${ }^{21}$ is unclear about where in the mental health system EIS should 
ideally sit; they are treated mainly as tertiary services, sitting behind front-line services. Nevertheless, placing EIS in the frontline will not be a panacea for DUP reduction, since whatever service is placed there will have the difficult task of differentiating psychosis from the complexity of referrals mental health services routinely receive; however, we note that in $70 \%$ of our sample accessing care via CMHTs, psychotic symptoms were recorded. How should mental health services ideally be configured? There has been considerable debate in the UK about the future structure of mental health services and the role of $\mathrm{CMHTs}^{37}$ on the one hand, and specialised teams on the other. Our findings suggest that CMHTs may not be ideal service structures for engaging and treating young people with a first episode of psychosis. What these data add is a considerable note of caution regarding initiatives to 'rebalance' services towards generic services, as this might risk disengagement and prolong DUP. The recent report of the UK Schizophrenia Commission into the current status of treatment and services ${ }^{38}$ has argued that 'We want the values and ethos of [Early Intervention in Psychosis] to spread across the entire mental health system'. These values include one of psychosis specialisation; perhaps then, within any generic front-line service, a psychosis pathway is needed to improve recognition, engagement and treatment delivery.

\section{Findings from modelling the impact of reducing delays}

Although no universal critical threshold for DUP has been agreed, our conservative threshold of 6 months was informed by existing literature and has highlighted the benefit of treating psychosis as early as possible within this 6 -month period. ${ }^{18}$ In our study $33.5 \%$ of clients were above this threshold. Their delays were not trivial, with a mean of 704 days and median of 518 days. We also replicated previous research ${ }^{18}$ demonstrating that those with DUP above 6 months experience more positive symptoms and general psychopathology early in the course, with effect sizes of 0.27 and 0.3 respectively.

We modelled the impact on DUP of reducing help-seeking and mental health service delays in order to establish the scale of change necessary to reduce the number with long DUP. We had expected help-seeking delay to be the major contributor to long DUP; around a third of their DUP was, indeed, accounted for by poor help-seeking. However, $42 \%$ of their DUP was because of delays experienced within mental health services, particularly in accessing EIS. In order to begin to have an impact on those individuals with a long DUP we would need to experimentally reduce mental health service delays to 2 months or less in order to see a reduction in the numbers of young people put at risk of poor outcome. To put this into context, the UK Department of Health Cancer Reform Strategy, ${ }^{39}$ reports that $99 \%$ of referrals for suspected cancer are now seen by a specialist within 2 weeks and $99 \%$ receive treatment within a month of their referral. Our findings suggest that direct access to EIS may be one strategy by which we can achieve similar results in psychosis.

These data suggest that an experimental intervention designed to reduce the numbers of individuals with DUP of over 6 months to less than 6 months would predict an impact on positive symptoms with an effect size of approximately 0.3. In keeping with previous research, ${ }^{40}$ we could identify no unique, defining demographic characteristics of those with long DUP, with the exception of a younger age at onset, which we interpret as arising from the difficulties of identifying the 'psychosis signal' from the psychopathological 'noise' of adolescence, hence delaying diagnosis and treatment. This is emphasised by the fact that, although only $6 \%$ of the whole cohort had a first referral to
CAMHS, $60 \%$ of those with long DUP experienced their onset between the ages of 16 and 18 years, compared with $27 \%$ of those with a short DUP. It is well documented that discontinuity in care can occur at the CAMHS-adult interface, ${ }^{13}$ which may have been a factor in delaying engagement and treatment.

The delay we have observed within mental health services makes it difficult to argue that DUP is due solely to patient factors, although it is possible that poor help-seeking and social withdrawal have an impact on engagement.

\section{Strengths and limitations}

The setting of this study, the second largest city in the UK, with notable ethnic diversity, is typical of cities in the UK. Although there may be some variation in the configuration and organisation of EIS, CMHTs and referral pathways across the UK, this service structure is largely typical of such services: locality-based CMHTs supported by functional teams including home treatment, assertive outreach and early intervention teams. We were able to sample extensively in this setting and thus the findings will have resonance nationally and internationally, given that these teams are becoming part of the landscape of care in many countries.

Although almost three-quarters of patients new to EIS consented to take part in the study, we were, however, unable to consent $30 \%$ of the original sample. Non-consenters are often difficult to engage and we cannot be certain that they did not experience long care-pathway delays and DUP. If this is the case, then our findings will underestimate DUP. On the other hand, should the non-consenters have experienced an exemplary pathway and a short DUP, this would still leave approximately $24 \%$ with DUP $>6$ months.

By definition DUP requires retrospective corroboration of symptomatology; however, psychotic status was confirmed by OPCRIT diagnosis at entry into EIS and documentation of presentation at entry into the National EDEN study. We note however, that in $70 \%$ of those in contact with generic mental health teams, psychotic symptoms were recorded by the responsible psychiatrist.

In the introduction we addressed the issue of implementing a public health intervention, along the lines of the Norwegian TIPS study. ${ }^{41}$ Our findings suggest that any improvement in help-seeking delay achieved by carrying out a public health initiative alone, could be undone if individuals continue to be directed into mental health services as currently configured. Whereas these data will be generalisable across English mental healthcare services, we suggest that the analytical approach we have adopted in order to understand the impediments to treatment within the care pathway, will have international application.

Max Birchwood, PhD, DSC, CPsychol, FBPSS, School of Psychology, University of Birmingham and YouthSpace Mental Health Service, Birmingham and Solihull Menta Health Foundation Trust, Birmingham; Charlotte Connor, PhD, CLAHRC Birmingham \& Solihull Mental Health Foundation Trust and University of Birmingham, Birmingham; Helen Lester (deceased) MB, BCH, MA, MD, FRCGP, previously at Primary Care Clinical Sciences, School of Health and Population Sciences, University of Birmingham, Birmingham; Paul Patterson, PhD, YouthSpace, Birmingham \& Solihull Mental Health Foundation Trust, and University of Birmingham, Birmingham; Nick Freemantle, $\mathrm{PhD}$, Department of Primary Care and Population Health, UCL Medical School (Royal Free Campus), London; Max Marshall, MBBS, MD, University of Manchester; David Fowler, PhD, Faculty of Medicine and Health Sciences, University of East Anglia, Norwich; Shôn Lewis, MD, University of Manchester; Peter Jones, MBBS, PhD, Department of Psychiatry, University of Cambridge, Cambridge; Tim Amos, MBBS, MRCPsych, Academic Unit of Psychiatry, Bristol; Linda Everard, BSC, Super EDEN, MRCPsych, Academic Unit of Psychiatry, Bristol; Linda Everard, BSC, Super EDEN,
Birmingham \& Solihull Mental Health Foundation Trust, Birmingham; Swaran P. Singh, MBBS, MD, FRCPsych, DM, Mental Health \& Wellbeing, University of Warwick, Coventry, UK

Correspondence: Max Birchwood, PhD, DSC, CPsychol, FBPsS, School of Psychology, University of Birmingham, Edgbaston, Birmingham B15 2TT, UK. Email: m.j.birchwood.20@bham.ac.uk

First received 21 Dec 2012, final revision 27 Mar 2013, accepted 3 Apr 2013 


\section{Funding}

This research was funded by the National Institute of Health Research as part of the National EDEN study. M.B, C.C., P.P. and S.P.P are part funded by the National Institute of Health Research CLAHRC (Collaboration for Leadership in Applied Health Research and Care) Birmingham and The Black Country.

\section{Acknowledgements}

Professor Helen Lester our colleague, friend and co-author, sadly died before the publication of this paper. Helen worked tirelessly throughout her career as a general practitioner and academic to address health inequalities, particularly in relation to severe mental illnesses. It was our privilege to work with Helen on the National EDEN studies, in which she acted as joint chief investigator, and to benefit from her passion, skills and knowledge. She will be sorely missed.

\section{References}

1 Johnstone EC, Crow TJ, Johnson AL, MacMillan JF. The Northwick Park study of first episodes of schizophrenia. I: Presentation of the illness and problems relating to admission. Br J Psychiatry 1986; 148: 115-20.

2 McGlashan TH. Duration of untreated psychosis in first-episode schizophrenia: marker or determinant of course? Biol Psychiatry 1999; 46: 899-907.

3 Barnes TRE, Hutton SB, Chapman MJ, Mutsatsa S, Puri BK, Joyce EM. West London first-episode study of schizophrenia. Clinical correlates of duration of untreated psychosis. Br J Psychiatry 2000; 177: 207-11.

4 Ho B, Andreasen NC, Flaum M, Nopoulos P, Miller D. Untreated initial psychosis: its relation to quality of life and symptom remission in firstepisode schizophrenia. Am J Psychiatry 2000; 157: 1183-8.

5 Marshall M, Lewis S, Lockwood A, Drake R, Jones P, Croudace T. Association between duration of untreated psychosis and outcome in cohorts of firstepisode patients. A systematic review. Arch Gen Psychiatry 2005; 62: 975-83

6 Crumlish N, Whitty P, Clarke M, Browne S, Kamali M, Gervin M, et al. Beyond the critical period: Iongitudinal study of 8-year outcome in first-episode non-affective psychosis. Br J Psychiatry 2009; 194: 18-24.

7 Lincoln CV, McGorry PD. Who cares? Pathways to psychiatric care for young people experiencing first-episode psychosis. Psychiatr Serv 1995; 46: $1166-71$.

8 Melle I, Larsen TK, Haahr U, Friis S, Johannessen JO, Opjordsmoen S, et al. Reducing the duration of untreated first-episode psychosis: effects on clinical presentation. Arch Gen Psychiatry 2004; 61: 143-50.

9 Tait L, Upthegrove R, Birchwood M, Ross $\mathrm{K}$, Brunet $\mathrm{K}$, McCollum R, et al. The evolution of depression and suicidality in first episode psychosis. Acta Psychiatr Scand 2010; 122: 211-8.

10 World Health Organization. The World Health Report 2001. Mental Health New Understanding, New Hope. WHO, 2001.

11 Lloyd-Evans B, Crosby M, Stockton S, Pilling S, Hobbs L, Hinton M, et al. Initiatives to shorten duration of untreated psychosis: systematic review. Br J Psychiatry 2011; 198: 256-63.

12 Lester HE, Birchwood M, Freemantle N, Michail M, Tait L. REDIRECT: cluster randomised controlled trial of GP training in first-episode psychosis. Br J Gen Pract 2009; 59: 183-90.

13 Singh SP. Early Intervention in psychosis. Br J Psychiatry 2010; 196: 343-5.

14 Brunet K, Birchwood M, Lester H, Thornhill K. Delays in mental health services and duration of untreated psychosis. Psychiatr Bull 2007; 31: 408-10.

15 Anderson KK, Fuhrer R, Malla AK. The pathways to mental health care of first-episode psychosis patients: a systematic review. Psychol Med 2010; 40 1585-97.

16 Lester H, Birchwood M, Bryan S, England E, Rogers H, Sirvastava N. Development and implementation of early intervention services for young people with psychosis: case study. Br J Psychiatry 2009; 194: 446-50.

17 Large M, Nielssen O, Slade T, Harris A. Measurement and reporting of duration of untreated psychosis. Early Interv Psychiatry 2008; 2: 201-11.
18 Drake RJ. Haley CJ, Akhtar S, Lewis SW. Causes and consequences of duration of untreated psychosis in schizophrenia. Br J Psychiatry 2000; 177 $511-5$.

19 Malla AK, Norman RM, Manchanda R, Ahmed MR, Scholten D, Harricharan R, et al. One year outcome in first episode psychosis: influence of DUP and other predictors. Schizophr Res 2002; 54: 231-42.

20 Office for National Statistics. Population estimates by ethnic group. ONS 2012 (http://www.statistics.gov.uk/hub/population/population-change/ population-estimates/index.html).

21 Department of Health. UK National Health Service Framework for EIS. Department of Health, 2001.

22 Birchwood M, Macmillan F. Early intervention in schizophrenia. Aus N Z J Psychiatry 1993; 27: 374-8

23 Birchwood M, Lester H, McCarthy L, Jones P, Fowler D, Amos T, et al. The UK National evaluation of the development and impact of early intervention services (The National Eden Studies): study rationale, design and baseline characteristics. Early Interv Psychiatry 2013; Jan 24 (Epub ahead of print).

24 World Health Organization. The ICD-10 Classification of Mental and Behavioural Disorders: Clinical Descriptions and Diagnostic Guidelines. WHO, 1992.

25 Kay SR, Fiszbein A, Opler LA. The Positive \& Negative Syndrome Scale (PANSS) for Schizophrenia. Schizophr Bull 1987; 13: 261-75.

26 Van den Oord EJ, Rujescu D, Robles JR, Giegling I, Birrell C, Bukszár J, et al. Factor structure and external validity of the PANSS revisited. Schizophr Res 2006; 82: 213-23.

27 Gater R, de Almeida e Sousa B, Barrientos G, Caraveo J, Chandrashekar CR, Dhadphale $\mathrm{M}$, et al. The pathways to psychiatric care: a cross-cultural study. Psychol Med; 21: 761-74.

28 Larsen TK, McGlashan TH, Moe LG. First episode schizophrenia: early course parameters. Schizophr Bull 1996; 22: 241-56.

29 Joint Formulary Committee. British National Formulary, 64. BMJ Group and Pharmaceutical Press, 2012.

30 Williams J, Farmer AE, Ackenheil M, Kaufmann CA, McGuffin P. A multicentre inter-rater reliability study using the OPCRIT computerized diagnostic system. Psychol Med 1996; 26: 775-83.

31 American Psychiatric Association. Diagnostic and Statistical Manual of Mental Disorders (4th edn) (DSM-IV). APA, 1994.

32 American Psychiatric Association. Diagnostic and Statistical Manual of Mental Disorders (3rd edn, revised) (DSM-III-R). APA, 1987.

33 Addington J, Addington D. Early intervention for psychosis: who refers? Schizophr Res 2006; 84; 176-7.

34 Platz C, Umbricht DS, Cattapan-Ludewig K, Dvorsky D, Arbach D, Brenner HD, et al. Help-seeking pathways in early psychosis. Soc Psychiatry Psychiatr Epidemiol 2006; 41: 967-74.

35 Cratsley K, Regan J, McAllister V, Simic M, Aitchison KJ. Duration of untreated psychosis, referral route and age of onset in an early intervention in psychosis service and a local CAMHS. Child Adolesc Ment Health 2008; 13: 130-3.

36 National Collaborating Centre for Mental Health. Schizophrenia: The NICE Guideline on Core Interventions in the Treatment and Management of Schizophrenia in Adults in Primary and Secondary Care (Updated Edition). The British Psychological Society and The Royal College of Psychiatrists, 2009.

37 Rosen A, Stein LI, McGorry P, Harvey C, Birchwood M, Diamond R. Specialist community teams backed by years of quality research. Psychiatrist 2013; 37: 38

38 The Schizophrenia Commission. The Abandoned IIIness: A Report by the Schizophrenia Commission. Rethink Mental Illness, 2012 (http:// www.schizophreniacommission.org.uk/the-report/)

39 Department of Health. Cancer Reform Strategy. Department of Health, 2007.

40 Morgan C, Fearon P, Hutchinson G, McKenzie K, Lappin, JM, Abdul-Al R, et al. Duration of untreated psychosis and ethnicity in the AESOP first-onset psychosis study. Psychol Med 2006; 36: 239-47.

41 Johannessen JO, McGlashan TH, Larsen TK, Horneland M, Joa I, Mardal S, et al. Early detection strategies for untreated first-episode psychosis. Schizophr Res 2001; 51: 39-46. 